\title{
Atom Probe Tomography Analysis of Bulk Chemistry in Mineral Standards
}

\author{
F. A. Laiginhas ${ }^{1}$, A. Perez-Huerta ${ }^{1}$, R. L. Martens², T. J. Prosa ${ }^{3}$, D. Reinhard ${ }^{3}$ \\ 1. Dept. of Geological Sciences, University of Alabama, Tuscaloosa, AL 35487 USA \\ 2. Central Analytical Facility, University of Alabama, Tuscaloosa, AL 35487 USA \\ 3. CAMECA Instruments, Inc., Madison, WI, 53711 USA
}

Atom Probe Tomography (APT) analysis of materials is an established technique for atomic level compositional analysis. Extensive research has been performed on many alloys, compounds, multilayered thin films, integrated circuits, and even polymers [1]. While some geological materials, mainly minerals and biominerals, have been previously studied [2-4], the use of APT for the resolution of bulk chemistry of minerals and its relationship to stoichiometry are insufficiently constrained. Often, the mass spectra from natural geological samples exhibit many complex ionic species, and their interpretation can lead to differing determinations of composition.

Utilizing the lift-out method for APT specimen preparation [5] (Fig. 1), APT analysis was performed on mineral standards of magnetite and pyrite with known elemental compositions [Magnetite $\left(\mathrm{Fe}_{3} \mathrm{O}_{4}\right): \mathrm{Fe}=71.88 \%, \mathrm{O}=27.53 \% ; \mathrm{Mn}=0.18 \%$ by mass; Pyrite $\left(\mathrm{FeS}_{2}\right): \mathrm{S}=53.45 \%$, $\mathrm{Fe}=46.55 \%$ by mass], to correlate to APT. Results indicate that the APT bulk atomic composition for magnetite underestimates the content of oxygen relative to iron based on the chemical formula, while overestimating the oxygen content based on the elemental composition of the standard (Fig. 2). For pyrite, APT results match the composition of sulfur and iron based on the molecular formula, but underestimate the composition of iron related to the measured elemental content in the standard (Fig. 2).

Based on these findings, two preliminary conclusions are presented: 1) For sulfides, and minerals with no oxygen, the atom probe is giving atomic proportions according to the molecular formula; and 2) For oxides, the atom probe underestimates the proportion of oxygen, likely due to complex interactions with cations, relative to the molecular formula.

Overall, our preliminary results indicate the need of further exploring the use of APT to obtain bulk chemistry for mineral samples, while providing basic operational procedures for sample preparation and standard development to be applied to more complex geologic samples in the future.

\section{References:}

[1] T.F. Kelly and M.K. Miller, Rev. Sci. Instrum. 78 (2007) p. 031101.

[2] K.H. Kuhlman et al., Ultramicroscopy 89 (2001) p. 169.

[3] J.W. Valley et al., Nature Geoscience 7 (2014) p. 219.

[4] L. Gordon and D. Joester, Nature 469 (2011) p. 194.

[5] D. Lawrence et al., Microscopy and Microanalysis 12 (2006) p. 1742.

Acknowledgments: This research was funded by the United States National Science Foundation (EAR-1402912) granted to APH. 


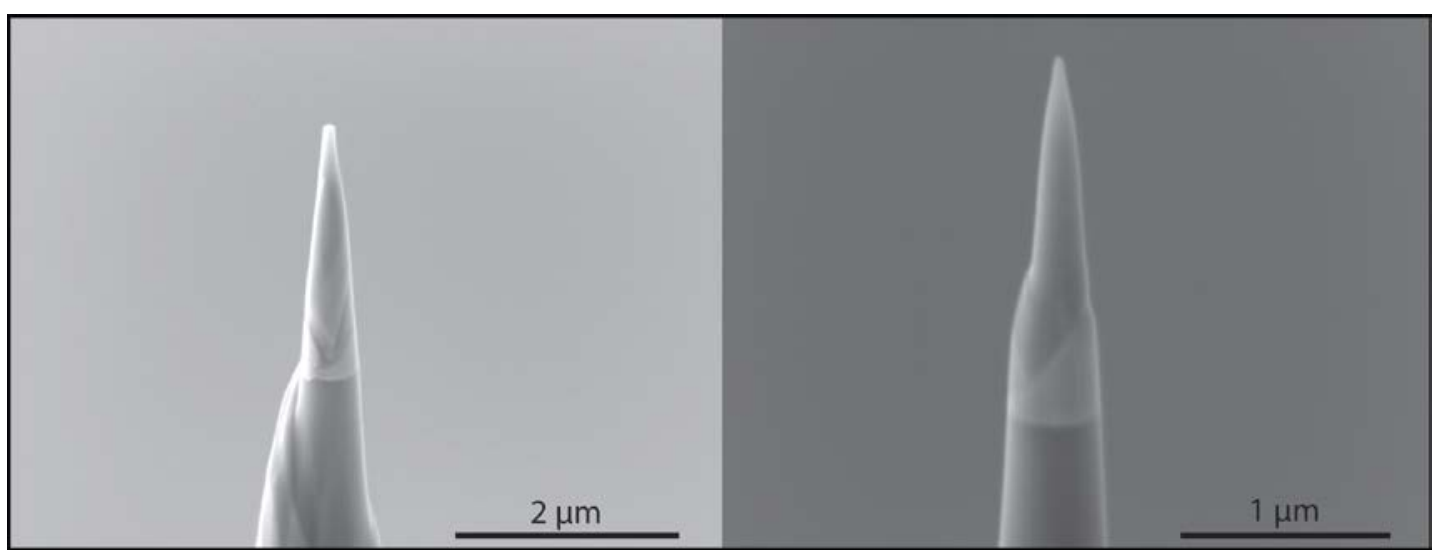

Figure 1. Example of focus ion beam (FIB) mineral sample tips, magnetite (left) and pyrite (right) for atom probe (APT) analysis.

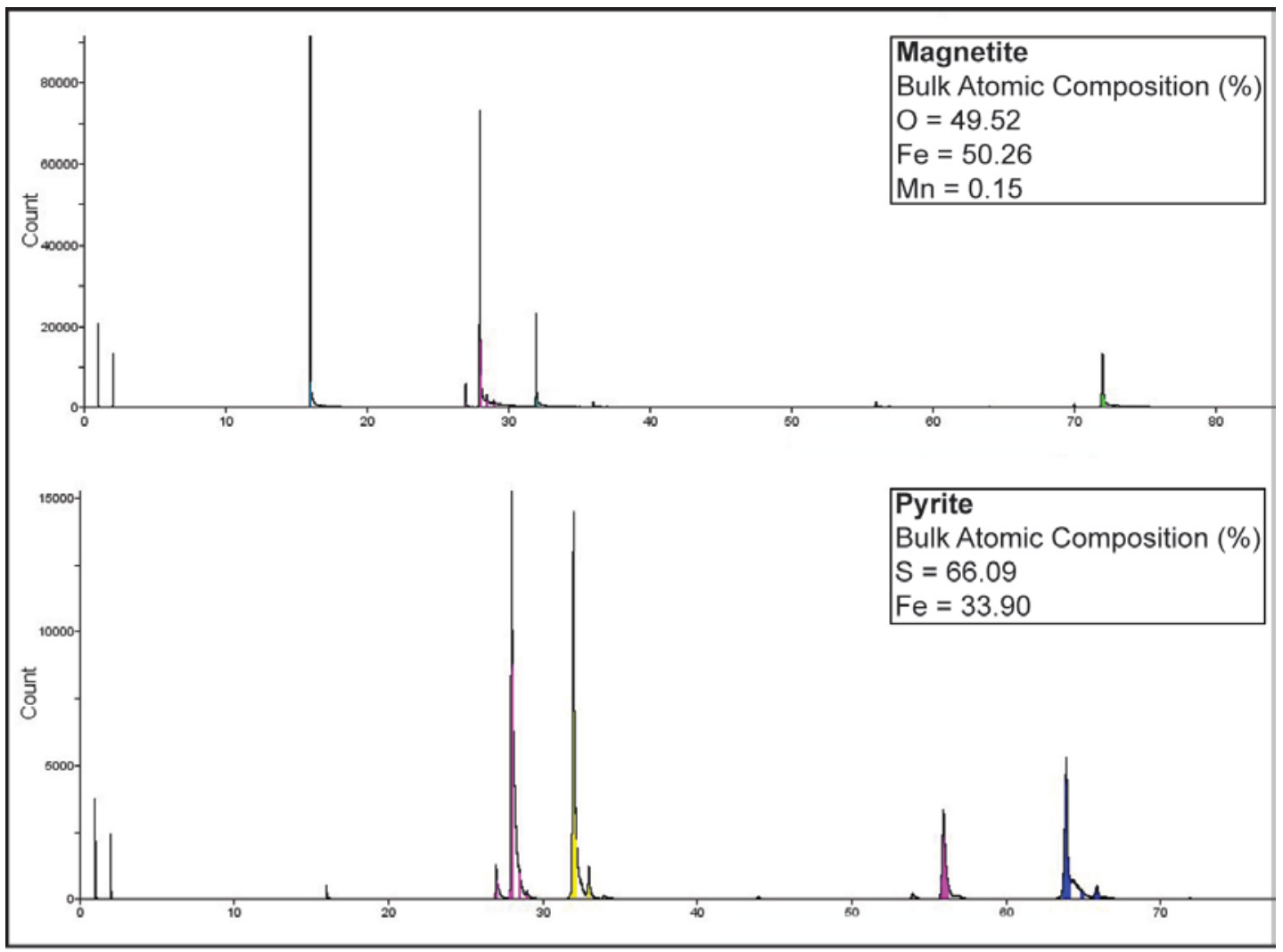

Figure 2. Example of APT mass spectra of magnetite (top) and pyrite (bottom) including the results for the bulk atomic composition. 